\title{
Variants of dermatofibroma - a histopathological study
}

\author{
JoãoVítor Pina Alves ${ }^{1}$ \\ Hugo Frederico Barreiros ${ }^{1}$
}

\author{
Diogo Miguel Matos ${ }^{1}$ \\ Elvira Augusta Felgueira Leonardo Fernandes Bártolo ${ }^{1}$
}

DOI: http://dx.doi.org/10.1590/abd1806-4841.20142629

Abstract: Several variants of dermatofibroma have been described. They are essentially distinguished by their
clinical and histopathological features. To review the mainfeaturesof these variants, a retrospective study of skin
biopsies and tissue excisions of dermatofibromasperformed in the dermatology and venereology service at the
Hospital Garcia de Orta between May 2007 and April 2012 was carried out. During that period, 192 dermatofibro-
mas were diagnosed in 181 patients, the lesions being more common in women. Median age of the study popula-
tion was 48 years. The most common lesion site was the limbs $(74 \%$ of patients). The histopathological types found
were common fibrous histiocytoma ( $80 \%)$ and the aneurysmal (5.7\%),hemosiderotic ( $5.7 \%)$, epithelioid ( $2.6 \%)$, cel-
lular ( $2.1 \%)$, lipidized $(2.1 \%)$, atrophic $(1.0)$ and clear cell $(0.5 \%)$ variants. Based on these findings, this review
focuses on the clinical and histological features of the various variants of dermatofibroma in terms of their clini-
cal presentation, distinct histopathological features, differential diagnosis and prognosis. Keywords: Histiocytoma; Histiocytoma, Benign Fibrous; Histology

\section{INTRODUCTION}

Dermatofibroma, also known as fibrous histiocytoma, is one of the most common cutaneous soft-tissue lesions, accounting for approximately $3 \%$ of skin lesion specimens received by dermatopathology laboratories. ${ }^{1}$ If the classical clinical and pathologic features are present the diagnosis is usually straightforward. However, in the presence of a variant diagnosis can be challenging. In addition to common fibrous histiocytoma, other variants described to date include aneurysmal, hemosiderotic, cellular, epithelioid, atypical, lipidized, clear cell, palisading, atrophic, keloidal, granular cell, myxoid, lichenoid, balloon cell and signet-ring cell variants. ${ }^{1-7}$ It is important to note that the histological features of several variants can coexist in the same lesion. ${ }^{2}$ Although histological features typical of a common fibrous histiocytoma are generally found, at least focally, the features of the above variants may represent the predominant component of the lesion, making identification of the histiocytoma more difficult. $^{3}$ Correct identification of these variants is important to avoid misdiagnosis of a possibly aggressive lesion. Furthermore, some variants have distinct clinical presentations and biological behavior, with different probabilities of local recurrence and, in rare and controversial cases, metastasis, making correct diagnosis even more important. ${ }^{3}$ This study seeks to review statistics on the variants of dermatofibromaseen in the Dermatology and Venereology Service at the Hospital Garcia de Orta and to characterize these pathologically and clinically.

Received on 18.03.2013.

Approved by the Advisory Board and accepted for publication on 24.04.2013.

* Study carried out at the Dermatology and Venereology Service, Hospital Garcia de Orta, Almada, Portugal.

Conflict of interest: None

Financial funding: None

Hospital Garcia de Orta - Almada, Portugal.

(C2014 by Anais Brasileiros de Dermatologia 


\section{MATERIALS AND METHODS}

A retrospective study of skin biopsies and tissue excisions of dermatofibromasperformed in our dermatology and venereology service between May 2007 and April 2012 was carried out. The clinical (age, gender, location of the lesion and clinical diagnosis) and histopathological features [variant, depth of invasion, epidermal changes (hyperkeratosis, acanthosis and basal layer hyperpigmentation) and the presence of lymphoid nodules or agrenz zone] were evaluated, and the clinical and histopathological characterization of the various variants was reviewed.

\section{RESULTS}

During the period studied, 192dermatofibromas were diagnosed in 181 patients. The lesions were more common in women than in men (124 and 57, respectively) (Graph 1). Patient age ranged from 11 to 80 years; median age was 48 . The most common location for the dermatofibromas was the limbs (74\%), followed by the trunk (23\%) and neck and face (3\%) (Graph 2). In $78 \%$ of the cases, the suspected clinical diagnosis was dermatofibroma. Of the remaining suspected diagnoses, the most common was non-specific nodular lesions $(6 \%)$, followed by melanocytic nevus

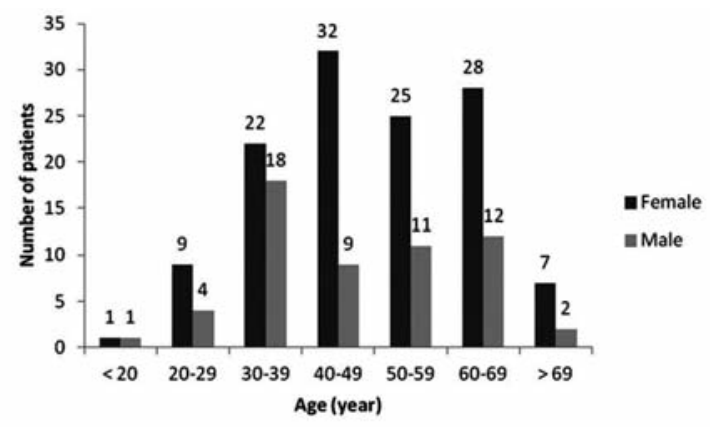

GRAPH 1: Age and gender distribution

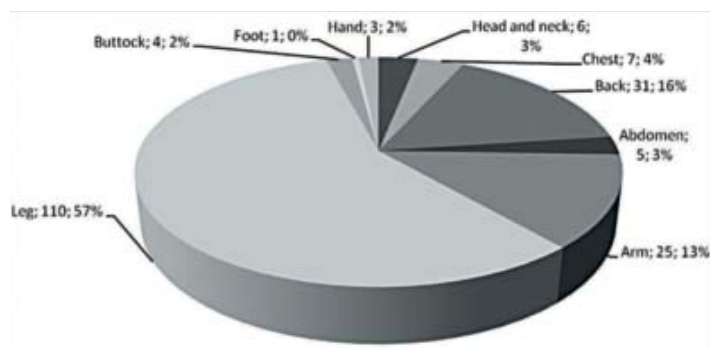

GraPH 2: Distribution of the lesions
$(4 \%)$, basal cell carcinoma (3\%), fibroma (2\%) and epidermal cyst, angioma and keloid (1\%).

The histopathologicaltypes found were common fibrous histiocytoma (80\%) and the aneurysmal $(5.7 \%)$, hemosiderotic $(5.7 \%)$, epithelioid $(2.6 \%)$, cellular $(2.1 \%)$, lipidized (2.1\%), atrophic (1.0) and clear cell $(0.5 \%)$ variants. In $69 \%$ of the cases, the lesion was found in the dermis, and in 31\% it had reached the subcutis. Subcutis involvement was more common in the aneurysmal and hemosiderotic variants $(81.8 \%)$. Hyperkeratosis, acanthosis and basal layer pigmentation were observedin $45 \%, 77 \%$ and $64 \%$ of the samples, respectively. Hyperkeratosis and basal layer pigmentation were more common in the cellular and lipidized variants $(75 \%)$ whereas acanthosis was more evident in cellular and atrophic dermatofibromas $(100 \%)$. A grenz zone was observed in $53 \%$ of the samples and was more evident in the atrophic and hemosiderotic variants $(100 \%$ and $64 \%$, respectively). Only $3 \%$ of the samples had lymphoid nodules in the dermal-subcutaneous junction (Table 1).

\section{DISCUSSION}

Dermatofibroma is one of the most common types of cutaneous soft tissue lesions. ${ }^{1}$ It is more frequent in middle-aged adults and has a slight female predominance. The majority of lesions are located on the limbs and present as small, raised, hyperkeratotic, cutaneous nodules with a red-brown surface. ${ }^{1,3} \mathrm{~A}$ significant proportion of dermatofibromas are associated with previous minor local trauma, especially insect bites. Eruptive lesions have been observed in the context of immunosuppression, HIV infection, highly active antiretroviral therapy (HAART) and pregnancy. ${ }^{4}$ Simple excision is usually curative, and local recurrence is rare, generally with rates of less than $2 \%$.

Several types of dermatofibromas have been reported in the literature ${ }^{1-7}$ They are essentially distinguished by their histopathological characteristics. However, it is important to note that the histological features of several variants can coexist in the same lesion. ${ }^{2}$ Some variants also have distinct clinical presentations as well as different rates of local recurrence, making correct diagnosis even more important.Rare cases of metastasis have also been described. ${ }^{3,5}$ However, the existence of metastatic dermatofibromas is the subject of considerable controversy, as dermatofibroma has until now been considered a benign lesion without the potential for distant dissemination.

Our experience supports the findings in the literature regarding patient age and gender and the location of the lesions. The correct preoperative diagnosis was made in $78 \%$ of the cases seen in our service. The other incorrect diagnoses reflect dubious clin- 
TABLE 1: Histopathological features of the several variants

\begin{tabular}{|c|c|c|c|c|c|c|c|}
\hline \multirow[t]{2}{*}{ Type } & \multirow{2}{*}{$\begin{array}{l}\text { Depth } \\
\begin{array}{l}\text { Dermis } \\
(\%)\end{array}\end{array}$} & \multicolumn{6}{|c|}{ Epidermal changes } \\
\hline & & $\begin{array}{l}\text { Subcutis } \\
(\%)\end{array}$ & $\begin{array}{l}\text { Hyperkeratosis } \\
(\%)\end{array}$ & $\begin{array}{l}\text { Acanthosis } \\
(\%)\end{array}$ & $\begin{array}{l}\text { BP } \\
(\%)\end{array}$ & $\begin{array}{l}\text { GZ } \\
(\%)\end{array}$ & $\begin{array}{l}\text { LN } \\
(\%)\end{array}$ \\
\hline Common & $118(76,6)$ & $36(23,4)$ & $70(46)$ & $119(77)$ & $102(66)$ & $84(55)$ & $5(6)$ \\
\hline Aneurismal & $2(18,2)$ & $9(81,8)$ & $2(18)$ & $8(73)$ & $7(64)$ & $6(55)$ & $0(0)$ \\
\hline Haemosiderotic & $2(18,2)$ & $9(81,8)$ & $5(45)$ & $9(82)$ & $5(45)$ & $7(64)$ & $0(0)$ \\
\hline Epithelioid cells & $5(100)$ & $0(0)$ & $3(60)$ & $3(60)$ & $2(40)$ & $0(0)$ & $0(0)$ \\
\hline Cellular & $2(50)$ & $2(50)$ & $3(75)$ & $4(100)$ & $3(75)$ & $1(25)$ & $1(25)$ \\
\hline Lipidized & $2(50)$ & $2(50)$ & $3(75)$ & $3(75)$ & $3(75)$ & $1(25)$ & $0(0)$ \\
\hline Atrophic & $2(100)$ & $0(0)$ & $0(0)$ & $2(100)$ & $1(50)$ & $2(100)$ & $0(0)$ \\
\hline Clear cell & $0(0)$ & $1(100)$ & $0(0)$ & $0(0)$ & $0(0)$ & $0(0)$ & $0(0)$ \\
\hline Total & $133(69)$ & $59(31)$ & $86(45)$ & $148(77)$ & $123(64)$ & $101(53)$ & $6(3)$ \\
\hline
\end{tabular}

BP: basal cell pigmentation; GZ: Grenz zone; LN: lymphoid nodules

ical manifestations or difficulties in the clinical differential diagnosis of dermatofibroma variants. For example, $18 \%$ of aneurysmal fibrous histiocytomas were clinically identified as angiomas. To help ensure accurate, correct identification of the various variants of dermatofibroma, we present a brief review of the literature on the distinct clinical and histopathological features of the variants observed in our sample.

\section{COMMON FIBROUS HISTIOCYTOMA}

As might be expected, this was the most frequently observed type in our study, accounting for 154 cases $(80 \%)$. The common variant is a non-capsulated, ill-defined dermal lesion that may extend into superficial subcutaneous fat (Figure 1). ${ }^{5,6}$ In the cases seen in our service, $76.6 \%$ involved the dermis and in $23.4 \%$ the lesionextended to the subcutis. The lesion is usually composed of interlacing fascicles of spindled cells, sometimes in a focal storiform arrangement, set within a loose collagenous stroma. The lesional cells include a variable admixture of fibroblasts, macrophages (some of which may be xanthomatous or multinucleated) and blood vessels. Some of the lesions (in our study, $55 \%$ of cases) are separated from the epidermis by a grenz zone. An inflammatory, predominantly lymphocytic infiltrate can sometimes be observed. ${ }^{3,56}$ Another helpful diagnostic feature is the presence of individual collagen bundles surrounded by lesional cells, imparting a somewhat hyalinized (sclerotic) appearance to the former (Figure 1). ${ }^{3}$ As observed in our study, many featuresare associated with epidermal changes (Figure 1). Generally, a hyperplastic epidermis, with hyperkeratosis, acanthosis or even pseudoepitheliomatoushyperplasia can be detected, as well as hyperpigmentation of the basal layer. Proliferation of hair follicle-like structures is not

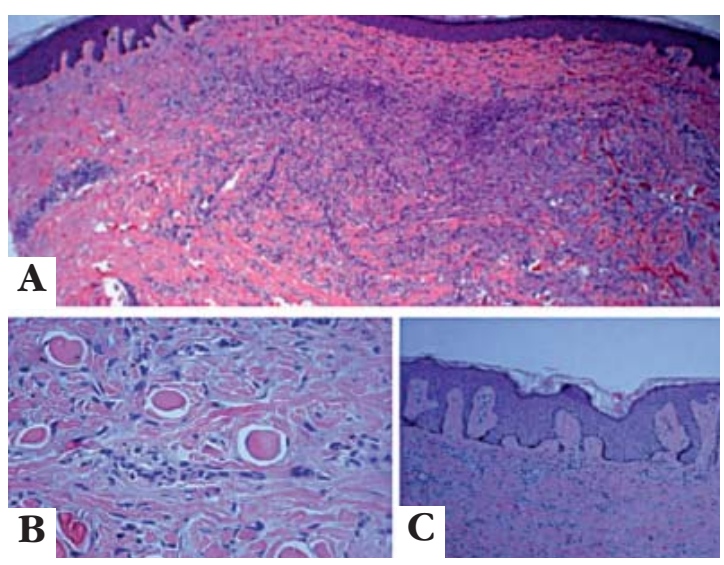

Figure 1: Common fibrous histiocytoma: A - An ill-defined noncapsulated dermal lesion composed of interlacing fascicles of spindled cells, in this case separated from the epidermis by a grenz zone (H\&E x 40); B - Globular collagen bundles at the periphery of the lesion (H\&E 100x); C - Associated epidermal changes: hyperkeratosis, acanthosis and basal cell layer hyperpigmentation (H\&E 40x)

infrequent and can mimic the features of basal cell carcinoma. ${ }^{5,7}$ Long-standing lesions are typically fibrotic or even sclerotic with decreased cellularity. ${ }^{5}$ Common fibrous histiocytoma is usually easy to diagnose, and problems with differential diagnosis generally only arise with other variants.

\section{ANEURYSMAL FIBROUS HISTIOCYTOMA}

Aneurysmal fibrous histiocytoma was first described by Santa Cruz et al. ${ }^{8}$ This variant usually represents less than $2 \%$ of dermatofibromas. ${ }^{3}$ Its clini- 
cal presentation can be slightly different from that of the common histiocytoma, and usually consists of a blue-brown nodule on the limbs. ${ }^{3}$ Rapid growth due to extensive hemorrhage can occasionally be seen, and clinical confusion with a melanocytic or vascular lesion is common, which would explain the high percentage of suspected angiomas in our sample. ${ }^{9}$ The rate of recurrence (around 19\%) is also higher than for common histiocytomas. ${ }^{5}$

Histologically, the most typical feature of this variant is the presence of irregular hemorrhagic cleftlike and cystic spaces without endothelial lining (Figure 2). Adjacent solid areas usually show highly cellular tissues typical of common fibrous histiocytoma. Focal interstitial hemorrhage and hemosiderin deposition is typical, and normal mitotic figures can be observed. ${ }^{3,9}$ In our series we observed very extensive infiltration of the subcutisin $81.8 \%$ of patients with this variant. This feature has also been described in other studies. ${ }^{1}$ The surrounding stroma contains abundant small capillaries with interstitial hemorrhage and hemosiderin deposition. ${ }^{3,5,9}$ In this type of lesion, differential diagnosis with angiomatoid fibrous histiocytoma and Kaposi sarcoma is important. The former is a distinct clinicopathological entity and tends to occur on the extremities of younger patients. It is associated with systemic symptoms, is usually subcutaneous and is composed of desminpositive monomorphic spindle to ovoid eosinophilic cells. ${ }^{3,5}$ The latter is characterized by slit-like spaces composed of CD34+ spindle cells containing erythrocytes, andlesional cells consistently show nuclear positivity for human herpesvirus 8.5

\section{HEMOSIDEROTIC FIBROUS HISTIOCYTOMA}

This variant was identified in 11 cases $(5.7 \%)$. Hemosiderotichistiocytoma probably represents a stage in the development of aneurysmal fibrous histiocytoma. The lesion is composed of numerous small vessels, extravasated erythrocytes and intra- and extracellular hemosiderin deposition due to hemorrhage (Figure 2) ${ }^{3,5}$ Like the aneurysmal variant, hemo- siderotichistiocytoma is also distinguished by its depth, with nine of our cases involving the subcutis. Acanthosis was also observed in a large number of cases $(82 \%)$. Differential diagnosis may include melanoma as well as other melanocytic and nonmelanocytic lesions.

\section{EPITHELIOID FIBROUS HISTIOCYTOMA}

Epithelioidhistiocytoma was originally described by Jones et al. ${ }^{10}$ Unlike most histiocytomas, it has a slight male predominance. Clinically, it presents as a polypoid red nodule, generally on the limbs, which is usually confused with pyogenic granuloma. ${ }^{3,5,11}$ Histologically, it is characterized as a welldemarcated lesion in the papillary and superficial reticular dermis surrounded by an epidermal collarette. The grenz zone is generally lacking. ${ }^{5,11}$ By definition, at least $50 \%$ of the lesion is composed of rounded or polygonal epithelioid cells with abundant eosinophilic cytoplasm and round nuclei containing small eosinophilic nucleoli (Figure 3). ${ }^{3}$ Mild nuclear pleomorphism and occasional regular mitosis can be found. A delicate collagenous stroma separates the lesional cells, which may become more sclerotic in older lesions. The presence of numerous small vessels located among epithelioid cells is also a common feature. ${ }^{3,5,11}$ The most important differential diagnosis is with Spitz nevus.Unlike in Spitz nevus, no junctional component or nesting is present in epithelioidhistiocytoma, and the cells are negative for melanocytic markers, such as S100 protein, melan A and HMB45.,

\section{CELLULAR FIBROUS HISTIOCYTOMA}

This variant generally represents less than $5 \%$ of cutaneous fibrous histiocytomas. ${ }^{5}$ Like epithelioid fibrous histiocytoma, cellular histiocytoma has a slight male predominance. ${ }^{12}$ Despite being more common in the extremities, it has a propensity to develop at unusual sites, such as the face, ears, hands and feet. ${ }^{3}$ It is also characterized by its high recurrence rate (up to $26 \%$ ). ${ }^{12}$ Although the subject of some debate, as mentioned before, metastasis to regional lymph nodes
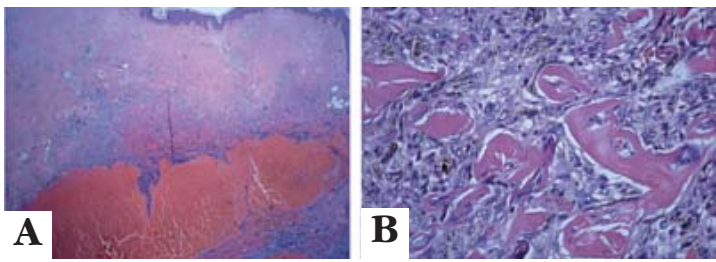

FIGURE 2: A - Aneurismal fibrous histiocytoma: a hemorrhagic space without endothelial lining (H\&E 40x); B - Hemosiderotic fibrous histiocytoma: hemosiderin deposition due to hemorrhage (H\&E 100x)

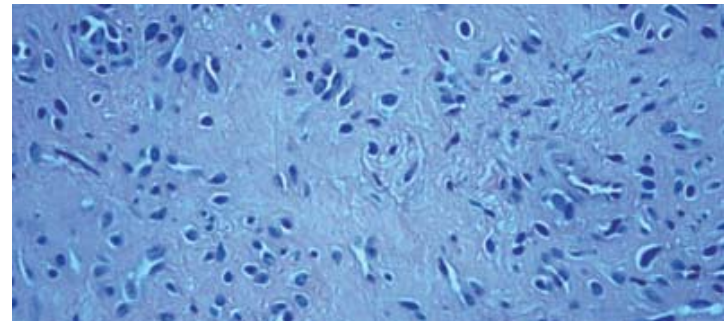

FIGURE 3: Epithelioid fibrous histiocytoma: rounded epithelioid cells with abundant eosinophilic cytoplasm (H\&E 100x) 
and lungs has also been reported in rare cases. It is important to note that, to date, histological features cannot be used to predict those cases that will eventually metastasize. ${ }^{5}$ Histologically, the lesions are highly cellular with a more prominent fascicular growth pattern. ${ }^{3}$ Lesional cells tend to have more abundant eosinophilic cytoplasm and generally are very infiltrative, extending into the subcutis. Normal mitosis is common, and areas of central necrosis or infarction may be found.$^{3,5,12}$ Features of ordinary fibrous histiocytoma can frequently be identified at the periphery of cellular areas. Curiously, in our study there was a high percentage of epidermal changes associated with this variant. Hyperkeratosis and hyperpigmentation of the basal cell layer were observed in $75 \%$ of cases, all of which had acanthosis. Immunohistochemical findings include variable (generally focal) SMA and calponin positivity and negative or only focal CD34 staining (especially at the periphery of cellular areas). Staining for factor XIIIa usually reveals a number of non-neoplastic cells in the background. ${ }^{3,12}$

The main differential diagnosis includes dermatofibrosarcomaprotuberans and leiomyosarcoma. The former shows extensive replacement of the subcutis and diffuse CD34 positivity, a monotonous, storiform growth pattern with monomorphous cells and cytogenetic evidence of the $t(17 ; 22)$ translocation. The latter shows spindle cells with cigar-shaped nuclei, at least focal cytological atypia, more uniform fascicular growth and more diffuse SMA and desminpositive cells. ${ }^{3,5}$

\section{LIPIDIZED FIBROUS HISTIOCYTOMA}

Lipidizedhistiocytoma was found in four cases in our study. The first study of a series withthis variant was reported by Iwata et al..$^{13}$ Informally, it has been called "ankle-type" fibrous histiocytoma because initial studies showed that this type of histiocytoma had a predilection for the lower extremities, especially around the ankle, although similar site and age distributions to those observed for common

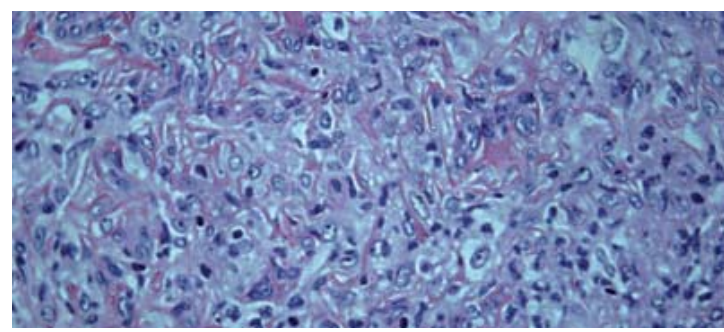

FIGURE 4: Lipidized fibrous histiocytoma: foamy cells surrounded by collagen bundles (H\&E 100x) fibrous histiocytomas were subsequently demonstrated. ${ }^{3}$ Clinically, it presents as a solitary exophytic yellow nodule usually larger than the common variant. ${ }^{3,5,13}$ It is apparently not associated with hyperlipidemia. ${ }^{3}$ Histologically, it is characterized by the presence of foamy macrophages surrounded by abundant sclerotic collagen bundles (Figure 4). . $, 5,13^{-13}$

Although follow-up data are limited, the prognosis appears to be good, with no recurrence even after incomplete excision. ${ }^{13}$

\section{ATROPHIC FIBROUS HISTIOCYTOMA}

This variant was found in two cases in our study and probably represents an end-stage of common fibrous histiocytoma. ${ }^{3,5}$ An early dermatopathologic study of atrophic fibrous histiocytoma was conducted by Zelger BW et al. ${ }^{14}$ Clinically, it presents as an area of depression or retraction, often resembling a scar, anetoderma or basal cell carcinoma., ${ }^{5,14}$ Atrophic histiocytoma is easily identified by its dermal atrophy with prominent sclerotic collagen and low cellularity. ${ }^{3}$ Although the cause of this histiocytoma is unknown, it has been postulated that dense elastic fibers around the vessels interfere with blood circulation, eventually causing dermal atrophy, or, alternatively, that the accumulation of elastic fibers results from dermal retraction, which also induces the compression of vessels. ${ }^{15}$

\section{CLEAR CELL FIBROUS HISTIOCYTOMA}

This is a very rare variant that was identified in one case in our study. Early references to this variant were made by Zelger BW et al. ${ }^{16}$ The lesion usually consists of sheets of clear cells with vesicular nuclei that occupy the reticular dermis and may extend into the subcutis (Figure 5). Cytological atypia and mitotic figures are rare. ${ }^{5}$ An overlying epidermal hyperplasia, a storiform arrangement of spindle cells, sclerotic collagen and an infiltrate of lymphocytes and macrophages at the periphery of the lesion can indicate the fibrohistiocytic origin of this lesion. ${ }^{17}$ In our
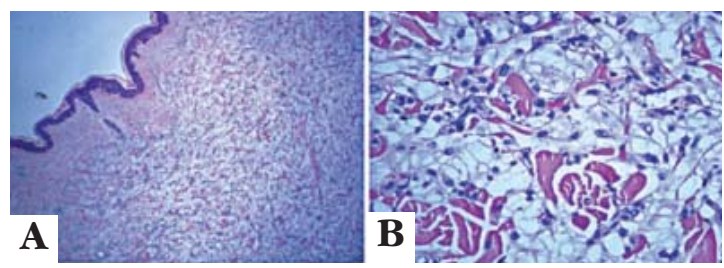

Figure 5: A - Clear cell fibrous histiocytoma: a lesion composed of clear cells occupying the reticular dermis (H\&E 40x); B. clear cells with vesicular nuclei in the reticular dermis (H\&E 100x) 
study this type of lesion was located in the dermis and subcutis. Unlike most variants, clear cell fibrous histiocytoma was not associated with epidermal changes. Clear cell dermatofibromais an uncommon variant with a difficult histological evaluation and must be differentiated from clear cell sarcoma and renal cell carcinoma metastasis.

\section{OTHER VARIANTS}

In addition to the variants observed in our study, others have been described in the literature. These include the atypical, palisading, keloidal, granular cell, myxoid, lichenoid, balloon cell and signetring cell variants. ${ }^{1,3,5}$

\section{REFERENCES}

1. Han TY, Chang HS, Lee JH, Lee WM, Son SJ.A clinical and histopathological study of 122 cases of dermatofibroma (benign fibrous histiocytoma). Ann Dermatol. 2011;23:185-92.

2. Zelger BG, Sidoroff A, Zelger B. Combined dermatofibroma: co-existence of two or more variant patterns in a single lesion. Histopathology. 2000;36:529-39.

3. Luzar B, Calonje E. Cutaneous fibrohistiocytictumours - an update. Histopathology. 2010;56:148-65.

4. Zaccaria E, Rebora A, Rongioletti F. Multiple eruptive dermatofibromas and immunossupression: report of two cases and review of the literature. Int J Dermatol. 2008;47:723-7.

5. Calonje E, Brenn T, Lazar A, Mckee P. Fibrohistiocytic tumors. In: Calonje E, Brenn T, Lazar A, Mckee P. McKee's pathology of the skin with clinical correlations. 4th ed. Edinburgh: Elsevier Saunders; 2012. p.1643-62.

6. Canelas MM, Cardoso JC, Andrade PF, Reis JP, Tellechea 0. Fibrous histiocytomas: histopathologic review of 95 cases. An Bras Dermatol. 2010;85:211-5.

7. Weedon D. Dermatofibroma (Fibrous histiocytoma). In: Weedon D. Skin pathology. 2nd ed. London: Churchill Livingstone; 2002. p.930-3.

8. Santa Cruz DJ, Kyriakos M. Aneurysmal ("angiomatoid") fibrous histiocytoma of the skin. Cancer. 1981;47:2053-61.

9. Calonje E, Fletcher CD. Aneurismal benign fibrous histiocytoma: clinicopathological analysis of 40 cases of a tumour frequently misdiagnosed as a vascular neoplasm. Histopathology. 1995;26:323-31.

\section{CONCLUSIONS}

The clinical and histopathological features of different variants of dermatofibroma were reviewed. Characterization of these variants is important for differential diagnosis and prognosis, since they have different probabilities of local recurrence and, in rare and controversial cases, metastasis. The authors hope that this study will facilitate differential diagnosis of fibrohistiocytic lesions in general and dermatofibroma variants in particular.
10. Jones EW, Cerio R, Smith NP. Epithelioid cell histiocytoma: a new entity. $\mathrm{Br} J$ Dermatol. 1989;120:185-95.

11. Singh Gomez C, Calonje E, Fletcher CD. Epithelioid benign fibrous histiocytoma of skin: clinic-pathological analysis of 20 cases of a poorly known variant. Histopathology. 1994;24:123-9.

12. Calonje E, Mentzel T, Fletcher CD. Cellular benign fibrous histiocytoma.Clinicopathologic analysis of 74 cases of a distinctive variant of cutaneous fibrous histiocytoma with frequent recurrence. Am J Surg Pathol. 1994;18:668-76.

13. Iwata J, Fletcher CD. Lipidized fibrous histiocytoma: clinicopathologic analysis of 22 cases. Am J Dermatopathol. 2000;22:126-34.

14. Zelger BW, Ofner D, Zelger BG. Atrophic variants of dermatofibroma and dermatofibrosarcoma protuberans. Histopathology. 1995;26:519-27.

15. Ohnishi T, Sasaki M, Nakai K, Watanabe S. Atrophic dermatofibroma. J Eur Acad Dermatol Venereol. 2004:18:580-3.

16. Zelger BW, Steiner H, Kutzner H. Clear cell dermatofibroma. Case report of an unusual fibrohistiocytic lesion.Am J SurgPathol. 1996;20:483-91.

17. Wambacher-Gasser B, Zelger B, Zelger BG, Steiner H.Clear cell dermatofibroma. Histopathology. 1997;30:64-9.

\author{
MAILING ADDRESS: \\ JoãoVítor Pina Alves \\ AvenidaTorrado da Silva, 2801-951 Almada, Portugal. \\ E-mail:alves.joaovitor@gmail.com
}

How to cite this article: Alves JVP, Matos DM, Barreiros HF, Bartolo EAFLF. Variants of dermatofibroma - a histopathological study. An Bras Dermatol. 89(3):472-7. 